\title{
The effect of dynamic recrystallisation on the rheology and microstructures of partially molten rocks
}

\author{
Maria-Gema Llorens ${ }^{\mathrm{a}, \mathrm{b}^{*}}$, Enrique Gomez-Rivas ${ }^{\mathrm{c}, \mathrm{d}}$, Anne-Céline Ganzhorn ${ }^{\mathrm{e}, \mathrm{f}}$, Albert Griera ${ }^{\mathrm{a}}$, \\ Florian Steinbach $^{\mathrm{b}}$, Jens Roessiger $^{\mathrm{b}}$, Loic Labrousse ${ }^{\mathrm{e}}$, Nicolas P. Walte ${ }^{\mathrm{g}, \mathrm{h}}$, Ilka Weikusat ${ }^{\mathrm{b}, \mathrm{i}}$ \\ and Paul D. Bons ${ }^{\mathrm{b}}$ \\ ${ }^{a}$ Departament de Geologia, Universitat Autònoma de Barcelona, 08193 Cerdanyola del Vallès, Barcelona, \\ Spain \\ ${ }^{b}$ Departament of Geosciences, Eberhard Karls University Tübingen, Wilhemstr. 56, 72074 Tübingen, Germany \\ ${ }^{c}$ Department of Mineralogy, Petrology and Applied Geology, University of Barcelona, Martí i Franquès $s / n$, \\ 08028 Barcelona, Spain \\ ${ }^{d}$ School of Geosciences, King's College, University of Aberdeen, AB24 3UE Aberdeen, United Kingdom \\ e Sorbonne Université, CNRS-INSU, Institut des Sciences de la Terre Paris, ISTeP UMR 7193, F-75005 Paris, \\ France \\ ${ }^{f}$ Laboratoire de Géologie de Lyon, UMR CNRS 5276, University of Lyon \& Ecole Normale Supérieure Lyon, \\ France \\ ${ }^{g}$ Bayerisches Geoinstitut, Universität Bayreuth, 95440 Bayreuth, Germany \\ ${ }^{h}$ Heinz Meier-Leibnitz centre for neutron science, TU München, Germany \\ ${ }^{i}$ Alfred Wegener Insitute for Polar and Marine Research, Bremerhaven, Germany \\ *Corresponding author: mariagema.llorens@uab.cat (Maria-Gema Llorens)
}

DOI: $\underline{10.1016 / j . j \mathrm{jg} .2018 .10 .013}$

This manuscript is published in the Journal of Structural Geology, 118, 224-235.

This is an author version of the article. For the final copy-edited version, please visit:

https://www.sciencedirect.com/science/article/pii/S0191814118302116

Keywords: partial melting; dynamic recrystallisation; microstructure; dihedral angle; simple shear, numerical simulation; 


\begin{abstract}
The present study is based on a series of two-dimensional simple shear numerical simulations of two-phase non-linear viscous materials used to investigate the mechanical behaviour of two-phase aggregates representing partially molten rocks. These simulations couple viscoplastic deformation with dynamic recrystallisation $(D R X)$. The aim of these simulations is to investigate the competition between deformation and recrystallisation, and how they affect the mechanical behaviour and resulting microstructures of the deforming material. We systematically vary the melt to solid rock ratio, the dihedral angle of melt and the ratio of $D R X v s$. deformation. The results show that the amount of $D R X$ and the dihedral angle have a first-order impact on the bulk rheology and the melt distribution in the aggregate. The numerical results allow defining two regimes, depending on the relative contribution deformation and $D R X:(1)$ a deformation-dominated regime at high strain rates (i.e., with a low ratio of recrystallisation $v s$. viscoplastic deformation) and (2) a recrystallisationdominated regime at low strain rates (i.e., with a high ratio of recrystallisation $v s$. viscoplastic deformation). The first case results in systems bearing large connected melt pockets whose viscous flow controls the deformation of the aggregate, while disconnected smaller melt pockets develop in models where dynamic recrystallisation dominates. The results of this study allow us to better understand the development of connected melt pockets, which may focus melt flow. The distribution of the melt phase plays a key role in the formation of larger scale melt-enriched shear bands, which in turn has a direct influence on large-scale convective mantle flow.
\end{abstract}

\title{
1. Introduction
}

Partial melting and subsequent melt transport are processes of primary importance for differentiation in the Earth, from core-mantle separation (Stevenson, 1990; Wood et al., 2006) to differentiation within the mantle and crust (Vielzeuf et al., 1990; Rudnick, 1995). In the present Earth, several studies suggest that the asthenosphere (Mierdel et al., 2007; Sifré et al., 2014), the ultra-low velocity zones at the core-mantle boundary (Lay et al., 2004), and even the large low-shear-wave velocity provinces (LLSVPs) (Hernlund and Houser, 2008; Hernlund and Tackley 2007) may contain limited percentages of silicate or metallo-sulphidic melt, which could explain the unusual rheological, seismic and electrical properties of these regions. Partial melting in the crust also has a strong effect on the bulk strength of the lithosphere during collision processes. Its weakening effect in the felsic crust has been for instance considered a key process in the exhumation of ultra-high pressure (UHP) rocks during continental subduction (Whitney et al., 2009; Labrousse et al., 2011) and in syn- to late-orogenic ductile flow of the lower crust in mature collision zones (Hollister and Crawford, 1986; Handy, 1990; Teyssier and Whitney, 2002; Vanderhaeghe, 2009).

Because of the important role of melt on the rheology of rocks, partially molten systems have been intensely investigated in experimental studies, and the impact of melt percentage on bulk strength (Rosenberg and Handy, 2005 and references therein), strain localisation (Holtzman and Kohlstedt, 2007) and the possible feedback relationships between strain and melting (Misra et al., 2009) have been analysed. However, it has also been shown that strain rate plays an important role in the distribution and rheological effect of melt, particularly when the melt-solid dihedral angle is high (e.g. Walte et al. 2011), which questions the use of laboratory studies whose strain rates are orders of magnitude faster than those acknowledged for melt-bearing shear zones. To better constrain the impact of partial melt on the bulk properties of aggregates, it is necessary to understand the complex interplay between melt 
and the crystalline matrix during deformation at geological strain rates that are not achievable in laboratory experiments.

The weakening effect of partial melting on the rock behaviour is mostly due to its very low strength compared to that of the solid. The bulk strength of the rock is thus an integral of the strengths of the different material phases, their proportion and the geometry of the weaker phase. Takeda and Obata (2003) argue that the viscosity $(\eta)$ of a partially molten rock decreases steadily with increasing melt fraction $(\phi)$. This can be described with an exponential law:

$$
\frac{\eta_{(\phi)}}{\eta_{(\phi=0)}}=\exp (-\lambda \phi)
$$

The parameter $\lambda$ depends on the dihedral angle $(\omega)$, which is the equilibrium angle between two solid-melt (SM) boundaries and a solid-solid (SS) boundary (see Table 1 for the list of symbols used). This equilibrium angle is determined by the relative surface energies $(J)$ of the SS and SM boundaries, according to:

$$
\omega=2 \cos ^{-1}\left(\frac{J_{S S}}{2 J_{S M}}\right)
$$

$\lambda$ was found to range between $\sim 21$ and $\sim 32$ for olivine aggregates with MORB (mid-ocean ridge basalt) melts ( $\omega \sim 30^{\circ}$; Mei et al., 2002; Scott and Kohlstedt, 2006) and to be $\sim 4$ for olivine aggregates with a metallic melt phase ( $\omega>60^{\circ}$; Hustoft et al., 2007). In the latter case the low value of $\lambda$ is partly associated with the compact shape of high-dihedral angle melt pockets. This compact shape results in isolated melt pockets whose deformation is constrained by the surrounding solid, load-bearing framework. The parameter $\lambda$ is higher at a low $\omega$, due to an increase in the solid-melt contact area and a decrease in the load-bearing capacity of the solid framework (Faul et al. 1994). Therefore, a metallic melt-bearing peridotite is stronger than one with basaltic melt (Hustoft et al., 2007). The weakening effect is not restricted to rocks containing melt, but also applies to materials bearing a second phase with a relatively lower viscosity, such as air bubbles within polar or glacial ice (Roessiger et al., 2014; Steinbach et al., 2017) and C-O-H fluids in the lower crust and upper mantle.

Table 1

Simulation setup

\begin{tabular}{llccc}
\hline Series & Simulation name & Dihedral angle $(\omega)$ & Melt fraction $(\phi)$ & DRX steps $\left(N_{D R X}\right)$ \\
\hline Series I & Simulation 1 & $30^{\circ}$ & $10 \%$ & 0.1 \\
& Simulation 2 & $30^{\circ}$ & $20 \%$ & 0.1 \\
& Simulation 9 & $173^{\circ}$ & $10 \%$ & 0.1 \\
& Simulation 10 & $173^{\circ}$ & $20 \%$ & 0.1 \\
\hline \multirow{2}{*}{ Series II } & Simulation 3 & $30^{\circ}$ & $10 \%$ & 10 \\
& Simulation 4 & $30^{\circ}$ & $20 \%$ & 10 \\
& Simulation 11 & $173^{\circ}$ & $10 \%$ & 10 \\
\hline \multirow{5}{*}{ Series III } & Simulation 12 & $173^{\circ}$ & $20 \%$ & 100 \\
& Simulation 5 & $30^{\circ}$ & $10 \%$ & 100 \\
& Simulation 6 & $30^{\circ}$ & $20 \%$ & 100 \\
& Simulation 13 & $173^{\circ}$ & $10 \%$ & 100 \\
\hline \multirow{5}{*}{ Series IV } & Simulation 14 & $173^{\circ}$ & $20 \%$ & 1000 \\
& Simulation 7 & $30^{\circ}$ & $10 \%$ & 1000 \\
& Simulation 8 & $30^{\circ}$ & $20 \%$ & 1000 \\
& Simulation 15 & $173^{\circ}$ & $10 \%$ & 1000 \\
\hline
\end{tabular}


The spatial distribution of melt, particularly its connectivity, is one of the main parameters controlling the effective weakening of partially molten rocks, especially when the melt fraction in the rock is relatively low (Cooper and Kohlstedt, 1984; Faul et al., 1994; Rosenberg and Handy, 2005; Kohlstedt and Holtzman, 2009). Indeed, for a given amount of melt a rock containing connected melt pockets (e.g., in sheet-like lenses) is significantly weaker than a rock in which pockets are isolated (Bons and Cox, 1994; Faul et al., 1994). The equilibrium distribution of melt in a non-deforming aggregate is controlled by the dihedral angle $(\omega)$ (Bulau et al., 1979; von Bargen and Waff, 1986; Rosenberg, 2001). Partially molten silicate rocks typically have low dihedral angles, which are assumed to be close to $30^{\circ}$ (e.g., Laporte and Watson, 1995), whereas Fe-Ni-rich melt in olivine or bridgmanite aggregates present higher values (between $60^{\circ}$ and $130^{\circ}$; see Terasaki et al., 2009). Air bubbles in glacial or polar ice are close to spherical, and therefore have $\omega \sim 180^{\circ}$ (Roessiger et al., 2011; Azuma et al., 2012; Faria et al., 2014; Steinbach et al., 2016).

In solid-melt aggregates, deformation perturbs the melt distribution by changing the shape of a volume of rock, and hence the shape of melt pockets. Moreover, a composite anisotropy can develop or be enhanced when two phases are present (Dabrowski et al., 2012). Viscous deformation tends to deform melt pockets more than solid grains, since melt is the weakest of the two phases (e.g., Mecklenburgh et al., 2003; Rutter et al., 2006; Jessell et al., 2009). This would result in characteristic microstructures with a certain melt pocket distribution and connectivity, which in turn would translate into a specific bulk rheology. However, the shape of solid grains and melt pockets can be constantly modified by recrystallisation processes (Walte et al., 2003). One important driving force for recrystallisation is grain boundary migration $(G B M)$, which is driven by surface energy and variations in strain energy (Urai et al., 1986). The resulting shape of melt pockets and their distribution within a deforming partially molten rock thus depend on the competition between deformation and grain boundary migration. In the absence of viscous deformation, melt distribution will achieve a dynamic equilibrium that is controlled by the surface energies of the interfaces between the various phases in the rock (Bulau et al., 1979; Von Bargen and Waff, 1986). This state of equilibrium can be disturbed if the rock is being deformed as a consequence of external loading. Experiments demonstrate that viscous deformation changes the shape of melt pockets, altering their distribution and potentially creating new structures such as melt-rich shear bands or fractures (Holtzman et al., 2003; Walte et al., 2005; Katz et al., 2006). Recovery from such disturbances of the equilibrium state is a time-dependent process. There are two regimes depending on the competition between viscous deformation and recrystallisation: (1) melt distribution is controlled by deformation at high strain rates and in systems with large grain sizes (resulting in a deformation-dominated regime) and (2) it is dominated by surface tension and recrystallisation at low strain rates and in rocks with small grain sizes, leading to a recrystallisation and surface tension dominated regime (Walte et al., 2011; Groebner and Kohlstedt 2006). Establishing the exact position of the boundary between these regimes is difficult since meaningful experimental studies need to be performed at a similar flow stress vs. surface tension ratio and/or strain rate $v s$. recrystallisation rate ratio as natural systems. As laboratory strain rates are several orders of magnitude too high, the high flow stress in previous experimental investigations had to be balanced by concentrating on systems with a higher solid-melt surface energy and by using much smaller grain sizes in experiments than in nature, which further enhances capillary forces (Walte et al. 2011). This allowed to trace the stress dominated vs. surface tension dominated boundary experimentally for the olivine $-\mathrm{FeS}$ melt, olivine - Au melt (Walte et al. 2011), and the olivine - FeS + basalt melt system (Cerantola et al. 2015). While olivine FeS deformation experiments by Todd et al. (2016) supported the results of Walte et al. 
(2011), a later study by Berg et al. (2017) was not able to reach the surface tension dominated regime under similar experimental conditions. The reason for this discrepancy is currently unclear. However, even if the boundary is firmly established in the experimental range, it has to be extrapolated over several orders of magnitude to natural conditions, which causes further uncertainty. This limitation of laboratory experiments can be overcome with numerical simulations that allow investigating the rheological and microstructural behaviour of partially molten rocks in all the spectra covering both regimes, because both length and time scales can be varied at will.

In this study, we use numerical modelling to investigate the microstructural and mechanical evolution of two-dimensional aggregates of solid grains with small to intermediate $(\leq 20 \%)$ percentages of low-viscosity melt, distributed in pockets between grains. Our two-phase simple shear simulations are performed using a full-field viscoplastic code (VPFFT; Lebensohn, 2001; Lebensohn et al., 2008) coupled with dynamic recrystallisation codes (Llorens et al., 2016a; 2016b; 2017; Steinbach et al., 2016; 2017) in order to investigate the mechanical behaviour of partially molten rocks in both recrystallisation- and deformation-dominated systems. We explore and compare systems with different melt fractions, dynamic recrystallisation $v s$. deformation ratios and dihedral angles. Although this work is primarily focused on partially molten rocks with low to moderate dihedral angles (i.e., $\omega \sim 30^{\circ}$ ), we also include simulations of rocks with dihedral angles of $\sim 173^{\circ}$. The latter would apply to air bubbles in ice, in which case one should read "air" for melt, or to sulphur-poor Fe-Ni-Si metal alloys in olivine or bridgmanite, in which case one should read "sulphur-poor Fe-Ni metal alloy" for melt.

\section{Methods and simulation setup}

\subsection{The numerical model}

The numerical simulation platform ELLE (http://www.elle.ws; Jessell et al., 2001; Bons et al., 2008), including the full-field viscoplastic code based on the Fast Fourier Transform algorithm (VPFFT; Lebensohn, 2001; Lebensohn et al., 2008), is used to study the microstructural and mechanical evolution of aggregates of solid grains (referred to as "solid") with a second phase, referred to as "melt". ELLE couples different processes acting on the microstructure in a sequential order for small time steps (Jessell et al., 2001). ELLE has been applied to a range of problems in geology (Bons et al., 2008), of which the most relevant to this study are simulations of static and dynamic grain boundary migration in single and twophase materials (Bons et al., 2001; Becker et al., 2008; Roessiger et al., 2011; Roessiger et al., 2014; Ran et al., 2018) and viscous or viscoplastic deformation either as a single process (Bons and Cox, 1994; Jessell et al., 2009; Griera et al., 2013; Llorens et al., 2013a; 2013b) or coupled with dynamic recrystallisation (Llorens et al., 2016a; 2016b; 2017; Steinbach et al., 2016; 2017; Gomez-Rivas et al., 2017). Jessell et al. (2009) and Ran et al. (2018) carried out a series of deformation simulations of two-phase aggregates up to relatively high shear strains. These authors did not include the effect of grain boundary migration on the microstructure evolution, although it is expected that this is a fundamental control especially at low strain rates and grain-scale phase regions. The effect of grain boundary migration is therefore incorporated in this study, together with a mechanical analysis of the deforming media, not yet included in Jessell et al. (2009).

The 2-D microstructure is defined in ELLE by a set of polygons in a two-dimensional section of the modelled material (Fig. 1a). Polygons are defined by a network of boundary 
nodes (bnodes) that are connected by straight segments (Fig. 1b). The solid grains and melt pocket regions are defined by polygons with a constant effective viscosity, which is high for solid and low for melt polygons. Therefore, three types of boundaries are present in the model, with each having different properties: (1) solid-solid, (2) solid-melt and (3) melt-melt. The latter has no physical meaning and has no effect on the microstructural evolution, but has to be used in the models in order to maintain the polygon topology. We deliberately do not display such boundaries in the figures.

A resolution of $256 \times 256$ Fourier points (unodes), resulting in a unit cell defined by 65,536 discrete unodes, was used to store physical properties within grains (Fig. 1c). Each unode represents a small area with a certain lattice orientation, defined by three Euler angles (Llorens et al., 2016a), and a dislocation density. The VPFFT code uses these unodes for the viscoplastic deformation calculations. The change of the position of bnodes is calculated according to the deformation velocity field and grain boundary migration $(G B M)$.

Both VPFFT and ELLE use both horizontally and vertically wrapping boundaries, so that the upper and lower parts of the model are connected, as well as the left and right ones (Fig. 1; Jessell et al., 2001). This makes the model periodic in all directions. Regions falling out of the square bounding box are repositioned within the box after each calculation step, so that the unit cell remains square through deformation in simple shear (see Fig. 1 in Llorens et al., 2016b). This approach considerably reduces boundary effects and facilitates visualisation of the deformation structures, even at very high shear strains.

The initial microstructure for all simulations is a polycrystalline aggregate consisting of solid grains and melt pockets created from an initial foam texture of solid grains (Fig. 1a). Melt polygons are inserted at all triple junctions between grains of the foam texture. Their initial size is determined by the imposed melt fraction $(\phi)$, which is set at $10 \%$ and $20 \%$ (see Table 1 for simulation settings). The aggregate is then equilibrated by static grain boundary migration until all melt pockets reach the imposed dihedral angle (i.e., $\omega=30^{\circ}$ or $\omega=173^{\circ}$; Fig. 1a, Table 1). To simulate the mechanical properties applicable to any solid phase, a hexagonal symmetry "model mineral" with equal critical resolved shear stress (CRSS) for basal and non-basal slip systems, was chosen (as in Griera et al., 2011). The ratio of CRSS for slip systems in the melt with respect to those in the solid was set to 100 . This value was chosen as a compromise between computational time and accuracy of the simulations (both increasing with increasing CRSS ratio). The same value of stress exponent of $n=3$ was set for all the slip systems in both melt (soft) and solid (hard) phases. This approach has been previously compared with an updated version of the VPFFT code (Lebensohn et al., 2011; 2013) that avoids any crystallography and imposes zero stiffness to unodes in the soft phase. As shown in Steinbach et al. (2016), the results are essentially the same using both approaches, validating the use of a CRSS ratio of one hundred. Solid grains have randomly assigned initial Euler angles for their lattice orientation (Fig. 1c). The initial microstructure is subjected to a loop of processes that includes VPFFT deformation and a subloop of dynamic recrystallisation processes, as $G B M$ and intracrystalline recovery (Fig. 1d). 

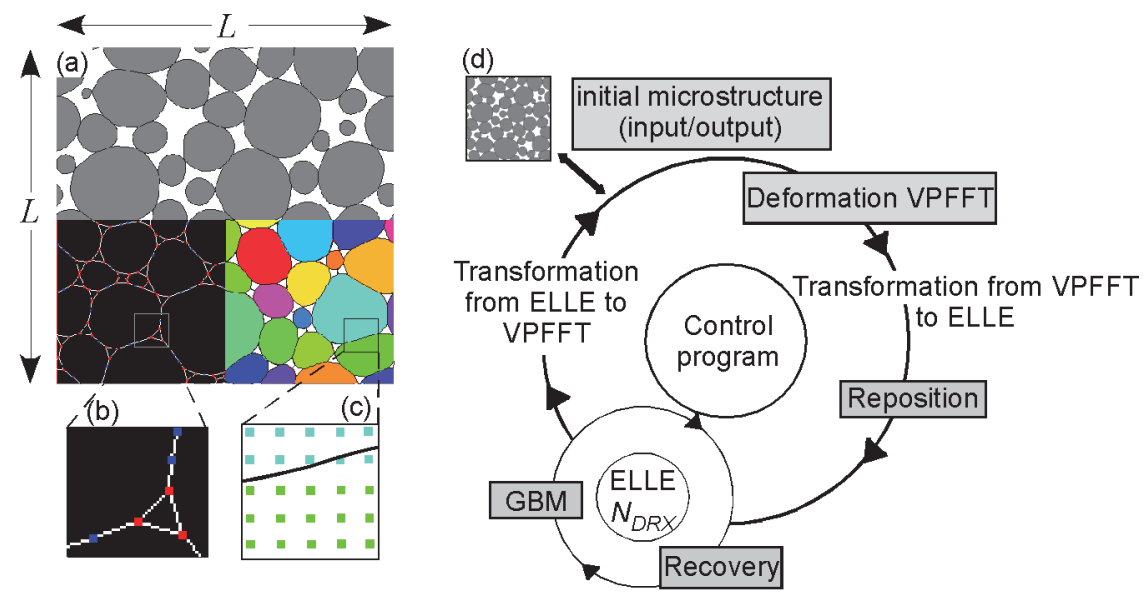

Figure 1. (a) Starting microstructure with melt fraction $\phi=20 \%$ for dihedral angle $\omega=30^{\circ}$. Solid grains are shown in grey, melt is displayed in white and polygon boundaries in black. (b) Polygons in ELLE are defined by boundary nodes (bnodes) that are connected by straight boundary segments that are connected at double (blue bnodes) and triple junctions (red bnodes). (c) Regular array of nodes (Fourier points) used for the VPFFT calculation. (d) Loop of processes every time step: one VPFFT deformation increment of dextral simple shear, followed by repositioning that brings the model back into the $L x L$ cell for the subloop of $N_{D R X}$ recrystallisation processes steps (GBM and recovery).

\subsection{Full-field viscoplastic deformation}

The anisotropic crystalline behaviour is defined using a non-linear viscous rate-dependent approach, where deformation at the grain scale is modelled as if accommodated by glide along predefined slip systems (in a power-law creep regime) (Lebensohn et al., 2001). The VPFFT formulation provides a solution of the micromechanical problem by finding a strain rate and stress field that minimises the average local work-rate under the compatibility and equilibrium constraints (see Lebensohn, 2001). The deformation-induced lattice rotation and the estimation of geometrically necessary dislocation (GND) densities calculated from the stress and velocity field are provided by the VPFFT (Llorens et al., 2016a; 2016b; 2017; Steinbach et al., 2016; 2017; Gomez-Rivas et al., 2017). The GND density associated with the lattice distortion (Ashby, 1970) is calculated from the plastic strain gradient (derived from Gao et al., 1999) assuming a constant Burger's vector for all slip systems (see Llorens et al., 2016a for a detailed description of the method).

All simulations are carried out in simple shear. Horizontal dextral simple shear is applied in incremental steps of $\Delta \gamma=0.02$ up to a shear strain of $\gamma=2$ (except for Simulation 5 in which $\gamma=4$ is reached). Taking advantage of the vertical wrapping of the model geometry, we use an algorithm to randomly apply these boundary conditions at a different level each step. This routine significantly reduces the inevitable influence of boundary conditions and spreads it equally throughout the model (Jessell et al., 2009; Llorens et al., 2013a; 2013b).

\subsection{Grain boundary migration and recovery}

For solid-solid boundaries, grain boundary migration is driven by the reduction of grain boundary energy and stored strain energy, reproducing the motion or displacement of highangle grain boundaries (HAGB, i.e., Karato, 2012). Grain boundary migration is modelled according to the poly-phase approach of Steinbach et al. (2016). The reader is referred to this publication for a complete description of the two-phase $G B M$ code. The routine moves single bnodes, depending on the driving stress on the boundary at each bnode. This driving stress is 
derived from the total grain boundary surface energy ( $E_{\text {surf }}$, the product of surface energy and boundary length) and the internal strain energy ( $E_{\text {strain, }}$, calculated from dislocation density field). The condition of $E_{\text {strain }}$ is reduced to zero in the area swept by the moving boundary is assumed. Bnodes are moved following the direction of maximum energy reduction and depending on the grain-boundary mobility ( $M$, a "frictional" term) in a way that the work done equals the change in the local energy state (see Becker et al., 2008).

The competition between surface $\left(\mathrm{E}_{\text {surf }}\right)$ and internal strain energies $\left(\mathrm{E}_{\text {strain }}\right)$ in the $G B M$ approach presented here, was investigated previously in Steinbach et al. (2016), showing that $G B M$ is mostly driven by internal strain energy in high-strain zones, while in low-strain zones the contributions of surface and internal strain energies are about equal (see Fig.5 in Steinbach et al., 2016).

The movement of solid-melt boundaries $(S M)$ is slightly more complex, since mass conservation needs to be considered. In this case, the driving stresses are the aforementioned surface energy $\left(J_{S M}\right)$ of the segment and a second energy term that takes into account the mass conservation between solid and melt. If a $S M$-node moves into a melt region, the area of this region is reduced by the amount $\Delta A$, while the solid region is expanded by $-\Delta A$. This implies a compression of the melt and a decompression of the solid phase because the region masses are kept constant. This process requires work and a change in the local energy state. The total local energy $\left(E_{t o t}\right)$ as a function of node position $(X)$ is therefore a function of the surface energy ( $E_{\text {surf }}$, see above) and the work related to change the area of the melt region $\left(A_{(X)}\right)$ in relation to the original or equilibrium area $\left(A_{0}\right)$ :

$$
E_{\text {tot }}(X)=E_{\text {surf }}(X)+a\left(\frac{A_{x}-A_{0}}{A_{0}}\right)^{2}
$$

where $a$ is a constant that determines the amount of area deviation that is allowed and can thus be regarded as a compressibility factor. The factor $a$ controls how quickly equilibrium between the two phases is reached. For further details, the reader is referred to Becker et al., (2008), Roessiger et al., (2014) and Steinbach et al. (2016).

Once the driving stress is determined, the velocity of the grain boundary is calculated from the mobility of the boundary for the different phases (MSS for solid-solid and $M_{S M}$ for solid-melt boundaries). Surface energies $\left(J_{S S}\right)$ and mobilities $\left(M_{S S}\right)$ of solid-solid boundaries of minerals are reasonably well constrained, as these can be derived from static grain growth experiments (e.g., Evans et al., 2001). Once the magnitude of $J_{S S}$ is known, $J_{S M}$ can be determined with Eq. 2) for a given dihedral angle of the solid-melt system. The magnitude of $M_{S M}$ is much less constrained, for which reason we consider here that $M_{S M}=M_{S S}$. To achieve different dihedral angles in our simulations, a constant unit $J_{S S}$ is used, and $J_{S M}$ is set at: $J_{S M} / J_{S S}=0.52$ for $\omega=30^{\circ}$ and $J_{S M} / J_{S S}=8.00$ for $\omega=173^{\circ}$ (cf. Eq. 1). Scaling of the numerical parameters to natural systems is discussed later (Section 4).

In this study, dynamic recrystallisation $(D R X)$ is simulated by grain boundary migration and intracrystalline recovery. Recovery reduces the intra-granular stored energy, simulating annihilation of dislocations and their rearrangement into low-angle subgrain boundaries (Llorens et al., 2016a). In the current approach, the creation of high-angle grain boundaries (HAGB) does occur, but their conversion to numerical grain boundaries (defined by bnodes) is not implemented (Steinbach et al., 2016; Llorens et al., 2017). The coupling of deformation and $D R X$ is achieved by applying each process in isolation in alternating steps 
(see Llorens et al., 2016a, 2016b, 2017). Strain has a constant incremental value. The GBM routine (Section 2.3), however, requires to be applied with a sufficiently small time step. Thus, we can vary the relative amount of dynamic recrystallisation by keeping the strain increment constant, and vary the number $\left(N_{D R X}\right)$ of $D R X$ steps (with constant time $\left.\Delta t_{(D R X)}\right)$ per deformation step. We use $\left(N_{D R X}\right)=0.1,10,100$, and 1000, covering four orders of magnitude in scaled strain rates, with $N_{D R X}=0.1$ representing the highest strain rate. A test confirmed that using $\Delta \gamma=0.0002$ and $N_{D R X}=1$ gives similar results as the combination of $\Delta \gamma=0.02$ and $N_{D R X}$ $=100$.

\section{Results}

\subsection{Simulations with low rate of dynamic recrystallisation $\left(N_{D R X}=0.1\right)$}

The highest strain rate series of simulations (with $N_{D R X}=0.1$ ) shows the deformation behaviour as a function of melt fraction in a system where the rate of dynamic recrystallisation with respect to deformation is low. Models are run with two different melt fractions $(\phi=10 \%$ and $20 \%)$ and with two different initial dihedral angles $\left(\omega=30^{\circ}\right.$ and $\omega=173^{\circ}$ ) (Figs. 2a, 3a) (Series I; Table 1).

In these simulations melt segregates from an initially random distribution in triple junctions into bands of stretched melt pockets oriented at small angle to the shear plane, separated by solid regions or "lenses", after a shear strain of $\gamma=2$ (see Simulations 1 and 2 in Fig.2b; and Simulations 9 and 10 in Fig.3b). These bands form anastomosing networks, with larger bands at higher angles connected by smaller bands at lower angles (Fig. 5a, e). Strain localises in these weak melt-rich bands when the rate of dynamic recrystallisation is low. A higher melt fraction leads to increased strain localisation in connected melt regions (Fig. 5a Column II and IV).

As expected, the presence of melt reduces the strength of the aggregate (Simulations 1, 2 in Fig.4a-b or 9, 10 in Fig.4c-d). Normalised shear stress $(\tau)$ (i.e. strength) vs. strain $(\gamma)$ curves reveal an initial hardening and a subsequent softening after a shear strain of $\gamma \sim 1$, for models with low $D R X$ rate (Series I, simulations 1, 2, 9 and 10; Fig.4), regardless of the initial dihedral angle as it is not preserved during deformation. However, the dihedral angle still has a moderate effect on the strength of the aggregate even when the $D R X$ rate is very low. The bulk shear stress is $\sim 15 \%$ higher for the model with $\omega=173^{\circ}$ compared to that for the simulation with $\omega=30^{\circ}$ (see Simulations 1 and 9 in Figs. 4a and Fig4c, respectively). This is probably due to differences in the geometry of melt pockets that remain, even up to a shear strain of two. The hardening and subsequent softening is reduced in systems with lower melt percentage $(\phi)$ (see comparison between simulations 1 and 2 or 9 and 10; Fig.4).

\subsection{Simulations with high rate of dynamic recrystallisation $\left(N_{D R X}=10,100\right.$ or 1000)}

A series of simulations similar to those presented in the previous section were also run with higher rates of dynamic recrystallisation relative to deformation. This was achieved by systematically varying the number of $G B M$ steps $\left(N_{D R X}=10,100\right.$ or 1000$)$ per constant deformation time step of $\Delta \gamma=0.02$ (Series II, III and IV. Table 1). 

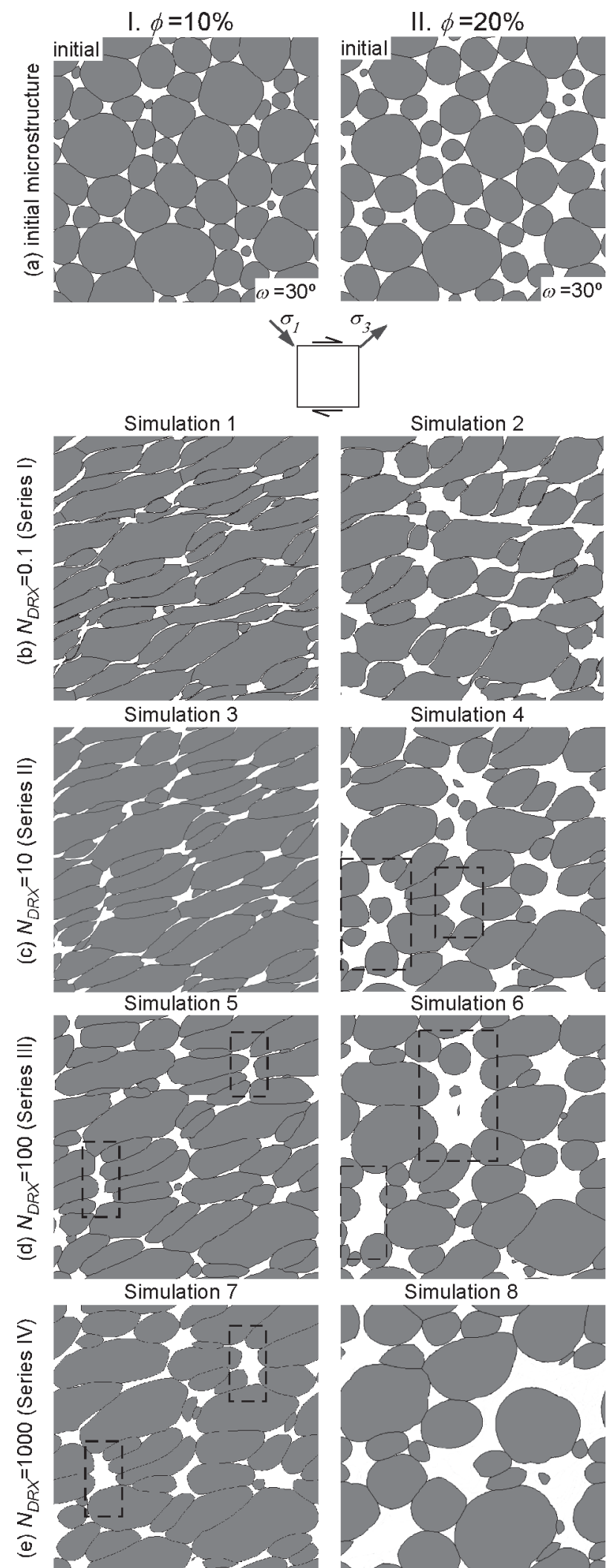

Figure 2. Effect of melt fraction $(\phi)$ and amount of recrystallisation $\left(N_{D R X}\right)$ on the resulting microstructures for simulations with a dihedral angle of $\omega=30^{\circ}$ and melt fraction of (I) $\phi=10 \%$, (II) and $\phi=20 \%$. All images correspond to a dextral shear strain of $\gamma=2$, for models (a) with $N_{D R X}=0.1$ (Series I, Table 1), (b) $N_{D R X}=10$ (Series II, Table 1), (d) $N_{D R X}=100$ (Series III, Table 1) and (e) $N_{D R X}=1000$ (Series IV, Table 1). The initial microstructure is shown in (a). Dashed rectangles indicate developed melt pools. 

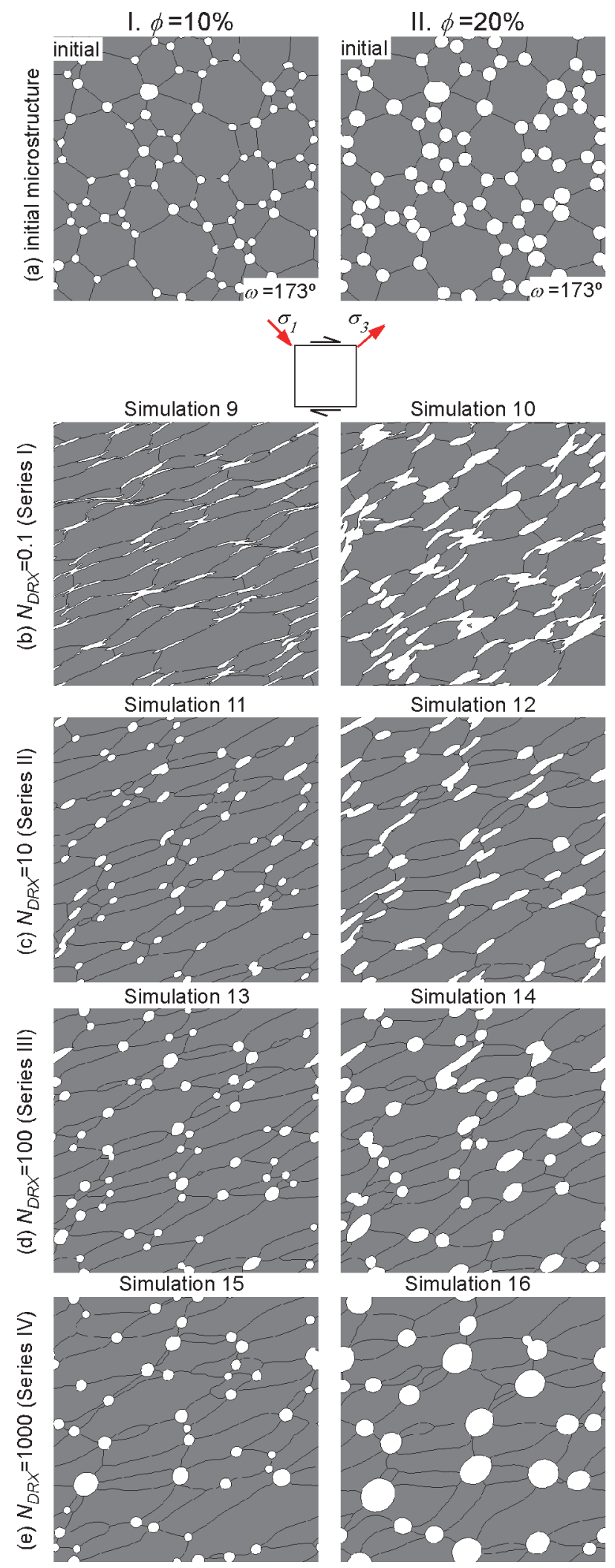

Figure 3. Effect of melt fraction $(\phi)$ and amount of recrystallisation $\left(N_{D R X}\right)$ on the resulting microstructures for simulations with a dihedral angle of $\omega=173^{\circ}$ and melt fraction of (I) $\phi=10 \%$ and (II) $\phi=20 \%$. All images correspond to a dextral shear strain of $\gamma=2$, for models (a) with $N_{D R X}=0.1$ (Series I, Table 1), (b) $N_{D R X}=10$ (Series II, Table 1), (d) $N_{D R X}=100$ (Series III, Table 1) and (e) $N_{D R X}=1000$ (Series IV, Table 1). The initial microstructure is shown in (a). 
In simulations with $\omega=30^{\circ}$, the high rate of dynamic recrystallisation $\left(N_{D R X}=10,100\right.$ or 1000) causes a dramatic change in the resulting microstructure (Fig. 2c-d-e), since it allows the melt pockets to retain their concave shape, which in turn results in initial melt pockets merging and forming larger pockets oriented at high angles with respect to the shear direction (see marked zones in Fig. 2c-d-e). In models with a low percentage of melt $(\phi=10 \%)$ melt pockets still appear elongated in the direction of the $X Y$ plane (Fig. 2c-d Column I) when $N_{D R X}$ is 10 or 100 . This elongation is not observed when $N_{D R X}$ is increased to 1000, because melt pockets retain then their initial dihedral angle (Fig. 2e Column I). Increasing $N_{D R X}$ also leads to melt pocket merging, resulting in an increase of both their average size and width of their size distribution (cf. Roessiger et al., 2014). The formation of melt chains is clearly observed when the melt fraction is increased to $\phi=20 \%$. In those simulations melt pockets get merged to form large melt pools (Fig. 2e Column II). Dynamic recrystallisation causes an increase of both grain size and melt pocket size, with the latter being more pronounced because of pocket merging.
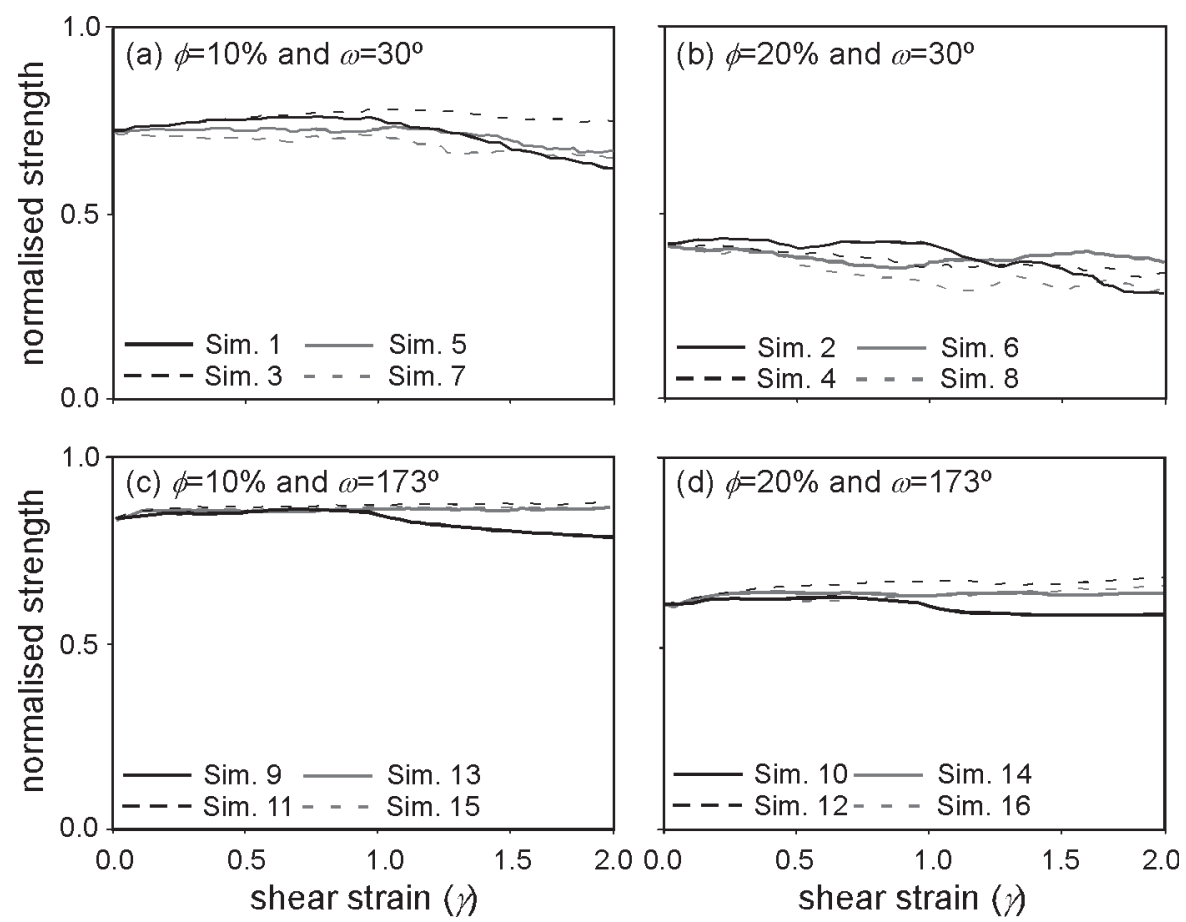

Figure 4. Evolution of the strength of the aggregates with progressive deformation for simulations with a dihedral angle of $\omega=30^{\circ}$ and melt fractions of (a) $10 \%$ and (b) $20 \%$. Simulations with a dihedral angle of $\omega=173^{\circ}$ and $10 \%$ and $20 \%$ of melt are shown in (c) and (d), respectively. The evolution of the strength is normalised to the strength of a solid single-phase simulation $(\phi=0 \%)$ in all cases.

$D R X$ reduces both the initial strain hardening and the subsequent strain softening, as it counteracts the stretching of melt pockets (Fig. 4). The only difference in the microstructure with increasing strain is a change in size and spacing of melt pockets, which leads to minor strain hardening. In simulations with low dihedral angles, the strain-induced change of the microstructure is primarily the merging of melt pockets in elongate pools almost perpendicular to the shear plane (Fig. 5b-d). This process suppresses the development of weak zones parallel to the finite stretching direction (Fig. 5b-d), and thus reduces the initial hardening and subsequent softening that is observed when $D R X$ rate is low (Fig. 4). At high dihedral angles $\left(\omega=173^{\circ}\right)$, melt pockets are mostly unconnected (Fig. 3c-e), which inhibits the development of high-strain melt pools (Fig. 5f-h). 
For simulations with high $D R X$ rate and low dihedral angles (Simulations 3 to 8), melt segregates forming networks of weak zones and strain partitions between weak and strong zones (Fig. 5b-d). As expected, strain partitioning is more pronounced in cases where the melt percentage is high (Fig.5 Column II). DRX enhances strain partitioning as it favours the merging of melt pockets in large weak zones. However, strain partitioning is not enhanced at high dihedral angles, as melt pockets do not segregate forming melt pools (Fig.5 Columns III and IV).

\section{Discussion}

Previous contributions have described the evolution of two-phase materials affected by deformation without including recrystallisation processes (e.g. Tullis et al., 1991; Bons and Cox, 1994; Treagus and Lan, 2000; Mancktelow, 2002; Madi et al., 2005; Takeda and Griera, 2006 and Jessell et al., 2009). In this contribution we present, for first time, a systematic study of the evolution of a two-phase microstructure using a full-field approach able to simulate viscoplastic deformation and including dynamic recrystallisation. This approach has been only applied before to study dynamic recrystallisation of firn in polar ice sheets (Steinbach et al., 2016). The simulations described in this paper are only two-dimensional and intentionally ignore a number of processes that are likely to occur in natural systems. Their utility is precisely that they provide a baseline to understand more complex systems and particularly to investigate the effect of coupling two fundamental processes: viscoplastic deformation and dynamic recrystallisation.

\subsection{Rheological effects}

For simulations with low $D R X$ rate (Series I, $N_{D R X}=0.1$ ) strain softening can be ascribed to the connection of melt pockets in the shear direction, eventually delineating a shear zone network localizing strain. Long axes of minerals in the solid matrix and connected shear melt pockets draw typical S-C' structures described in natural sheared rocks (Berthé et al., 1979). The stress-strain evolution at a low $D R X$ rate can be explained by the increasing stretching of melt pockets that is not counteracted by $D R X$. The developing anisotropy weakens the material for shearing parallel to the stretching direction, which is initially oriented at $45^{\circ}$ to the shear plane. However, as this direction is approximately perpendicular to the maximum compressive stress, the shear stress needed for horizontal shearing of the anisotropic medium is at first higher than that for the starting material. The shear stress decreases again steadily (after $\gamma \sim 1$ ) once anisotropy has developed enough and shear localisation bands rotate towards the horizontal shear plane (Takeda and Griera, 2006; Dabrowski et al., 2012).

When $D R X$ can contribute significantly to the microstructure, melt pockets merge from their initial distribution in triple junctions (Fig. 6a) to form bands perpendicular to the extension direction $\sigma_{3}$ at $\gamma=1$ (Fig. 6b). These bands continue rotating by shearing and eventually form melt pools oriented perpendicular to the shear plane (Fig.6c). After $\gamma=2$ melt pools rotate to the extensional field and get stretched while bands parallel to the extension direction continue merging (Fig. 6d-e). Experiments of sheared partially molten rocks performed by Qi et al., (2015; 2018) and Holtzman et al. (2003) show melt-enriched bands located at low angle to the shear plane. In our simulations the size of grains and melt pockets is similar to that in these experiments. However, the representative volume element in our simulations is not large enough to segregate melt pockets in bands as laboratory experiments show. Veining perpendicular to the stretching direction is also acknowledged in partially molten sheared natural rocks (Schulmann et al., 2008). 


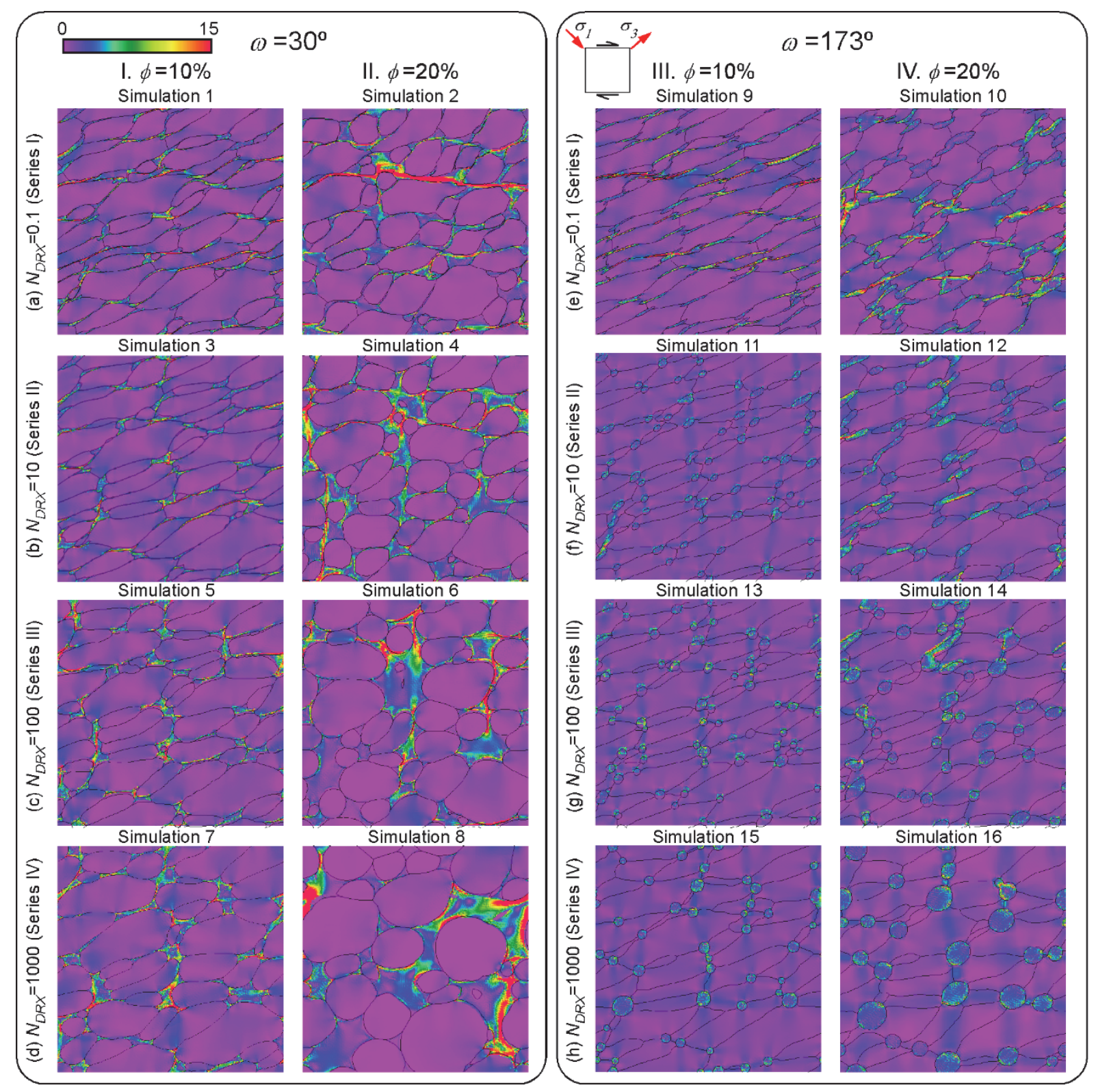

Figure 5. Von Mises strain rate field normalised to the bulk Von Mises strain rate for simulations with a dihedral angle of $\omega=30^{\circ}$ (columns I and II) and $\omega=173^{\circ}$ (columns III and IV) at a finite strain of $\gamma=2$. Different amounts of $D R X$ per deformation step are shown in (a, e) $N_{D R X}=0.1,(\mathrm{~b}, \mathrm{f}) N_{D R X}=10,(\mathrm{c}, \mathrm{g}) N_{D R X}=100$ and $(\mathrm{d}, \mathrm{h})$ $N_{D R X}=1000$. The percentage of melt is $\phi=10 \%$ and $\phi=20 \%$ in columns I and II respectively (Series I, II, III and IV for $\omega=30^{\circ}$ ) and columns III and IV (Series V, VI, VII and VIII for $\omega=173^{\circ}$ see Table 1). In simulations with low $D R X$ rate, high strain-rate bands are well aligned almost subparallel to the shear plane, which is horizontal in this figure. When dynamic recrystallisation rate is high, high-strain bands develop in simulations with $\omega=30^{\circ}$, that are oriented subperpendicular to the shear plane. However, in simulations with $\omega=173^{\circ}$ when the rate of dynamic recrystallisation is high, high-strain areas are located in the soft phase and are mostly unconnected. 

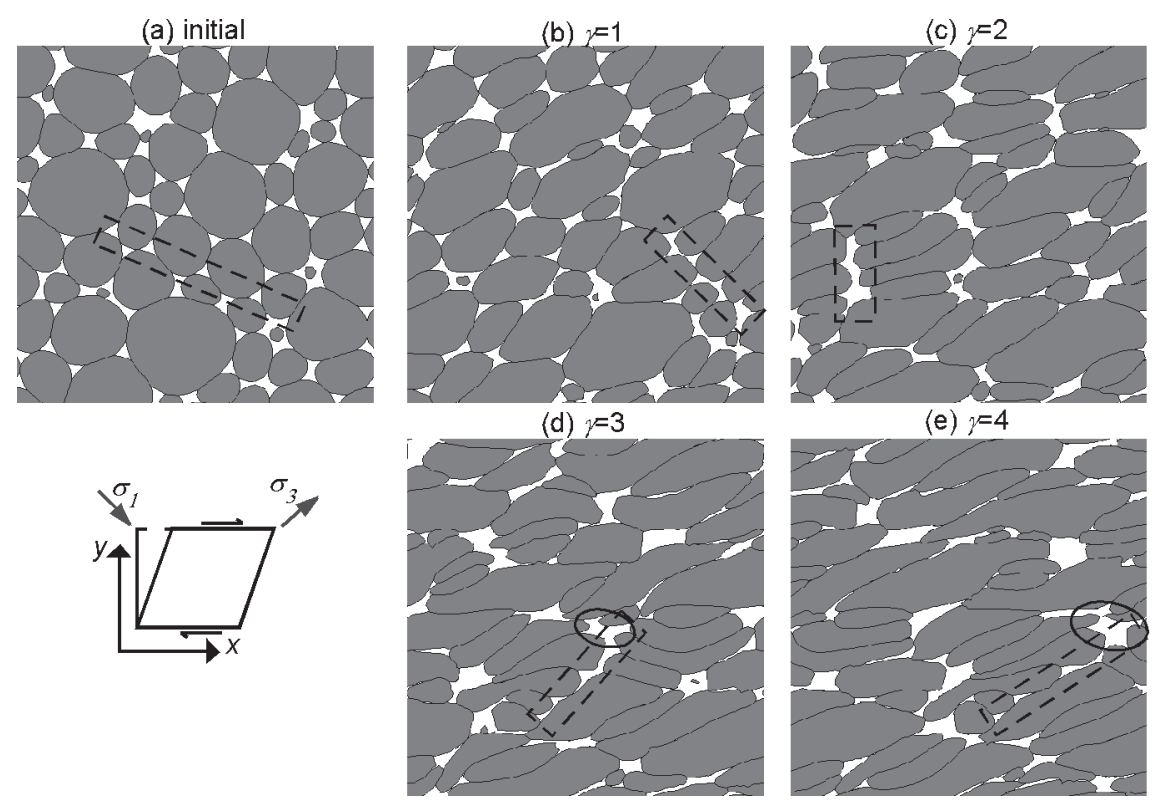

Figure 6. Evolution of the melt distribution of Simulation $5\left(\phi=10 \%, \omega=30^{\circ}\right.$; see Table 1$)$ up to a shear strain of $\gamma=4$, illustrating the developments and destruction of melt bands (indicated by dashed rectangles). (a) Initially homogeneous distribution of melt pockets at triple junctions. (b) Melt pockets merge in bands perpendicular to the extension direction $\sigma_{3}$ at $\gamma=1$ (dashed rectangle). (c) Melt pools start closing when they are oriented perpendicular to shear plane at $\gamma=2$. (d) Closed melt pools rotate to the extensional field and (e) the merging process in bands perpendicular to the extension direction continues (solid circle).

4.2. Comparison with laboratory experiments: dynamic recrystallisation-dominated vs. deformation-dominated systems

The effect of the dihedral angle and surface tension on rheology and melt distribution is twofold (Kohlstedt and Holtzman, 2009). First, there is a direct effect of surface tension and capillary forces on melt pockets or the melt network $\left(\omega \sim 30^{\circ}\right)$ that opposes the change of shape associated with deformation. The pressure difference $(\Delta P)$ between the melt and the solid can be expressed as a function of the solid-melt surface tension and the mean radius of curvature of the solid-liquid boundary of the melt pocket or network $(r)$, itself related to the grain size. The differential stress $\Delta \sigma$ must exceed capillary forces of a given melt pocket in order to cause a shape change in the first place. This can be calculated from the force balance between differential stress $(\Delta \sigma)$ and surface tension $\left(J_{S M}\right)$ (Walte et al., 2011):

$$
P_{t h}=\frac{\Delta P}{\Delta \sigma}=\frac{2 J_{S M}}{r \Delta \sigma}=\frac{2 J_{S M}}{r B(\dot{\varepsilon})(1 / n)}
$$

where $B$ and $n$ are parameters of the power-law equation that relates the differential stress to the strain rate $\left(\Delta \sigma=B(\dot{\varepsilon})^{1 / n}\right)$ and $P_{t h}$ is a non-dimensional parameter (Walte et al., 2011). This relation has previously been considered as dominant for the interplay of deformation with surface tension, and has accordingly been used to interpret and scale experimental results (Groebner and Kohlstedt, 2006; Walte et al., 2011; Cerantola et al., 2015). However, a second factor that has previously been largely ignored is the mobility of solid-melt grain boundaries $\left(M_{S M}\right)$. Even if $D_{s}$ (melt pocket diameter) is sufficiently high and Eq. 4 is fulfilled, the melt distribution (e.g., the melt pocket shape) can only be altered if the mobility of the solid-melt interface is sufficiently high. This mechanism depends on the product of surface 
tension and mobility and can be expressed with Eq. 5, which is modified from Kohlstedt and Holtzman (2009):

$$
P_{k i n}=\frac{J_{S M} M_{S M}}{r^{2} \dot{\varepsilon}}
$$

where $M_{S M}$ the mobility of a solid-liquid boundary. While Eq. 4 implies a division between a surface tension-dominated regime from a (differential) stress-dominated regime (cf. Walte et al., 2011), Eq. 5 implies a $D R X$-dominated regime distinct from a strain rate-dominated regime. However, in order to evaluate whether the melt distribution is altered by deformation, both equations must be fulfilled (Kohlstedt and Holtzman, 2009).

In order to compare our numerical simulations with laboratory experiments or natural rocks, length and time have to be scaled. The numerical simulations presented here show that the microstructural and rheological behaviour of the aggregate is determined by the opposing trends of a change in shape of melt pockets induced by deformation and their recovery towards an equilibrium shape produced by $D R X$. The first is related to the imposed strain rate, related to the stress associated with the aggregate viscosity, while the latter is controlled by the size of melt pockets and the ability of the solid-melt boundaries to move as a function of surface energy and mobility. Most authors propose a dimensionless thermodynamic scaling parameter that compares the imposed differential stress $(\Delta \sigma)$ to the surface energy and the mean melt-pocket radius ( $r$ ) (Eq. 4; Kohlstedt and Holtzman, 2009; Walte et al., 2011; Cerantola et al., 2015). As discussed above, this thermodynamic dimensionless number $\left(P_{t h}\right)$ does not consider the mobility of solid-liquid boundaries. It is clear from the numerical simulations that these boundaries would only move passively according to the imposed deformation if their mobility is set to zero (cf. Eq. 2). On the contrary, the kinematic dimensionless number $\left(P_{\text {kin }}\right)$ considers this boundary mobility (Eq. 5).

The choice of the two scaling parameters is far from trivial, since they predict very different scaling: $P_{t h}$ scales with strain rate to the power $1 / n$ and $r$, while $P_{k i n}$ scales with strain rate and $\mathrm{r}^{2}$. As our numerical model includes grain-boundary mobility, a proper scaling of these simulations can only be achieved by using the kinematic scaling parameter $P_{k i n}$. In order to scale our numerical simulations using $P_{k i n}$, we need to determine the surface energy $J_{S M}$ and the mobility $M_{S M}$. $J_{S M}$ can be determined with relative accuracy using Eq. 1 if $J_{S S}$ and the dihedral angle are known for the system under consideration (e.g., quartz with granitic melt - Laporte and Watson, 1995). $M_{S M}$ is relatively poorly constrained and depends on the actual mechanism of migration of solid-melt boundaries, involving dissolution-precipitation reactions as well as diffusion (Kohlstedt and Holtzman, 2009; Azuma et al., 2012). Here we assume, as in the numerical simulations, that $M_{S M}=M_{S S}$ (MSS being the mobility of solidsolid boundaries). The advantage is that the product $J_{S M} \times \mathrm{M}_{S M}$ can be determined if $J_{S S} \mathrm{x} M_{S S}$ and $\omega$ are known, through:

$$
J_{S M} M_{S M}=2 \cos (0.5 \omega) J_{S S} M_{S S}
$$

Natural values of $J_{S S}$ a MSS can be estimated from static grain growth experiments (e.g., Tullis and Yund, 1982). In case of grain growth controlled by the curvature of grain boundaries, the relationship between grain size $(D=2 r)$ and time $(t)$ is given by Evans et al. (2001):

$$
D_{(f)}^{2}-D_{0}^{2}=k M \gamma t
$$


Here $D_{0}$ is the initial grain size (which should be $<<D(t)$ ) and $k$ is a dimensionless parameter that depends on the microstructure (Roessiger et al., 2014) and on the number of dimensions of the system. For an equilibrated foam texture $k_{(2 D)}=4.48$ and $k_{(3 D)}=2$ (Mullins et al., 1989). The product $J_{S S} \mathrm{x} M S S$ for various minerals can thus be calculated from experimental data, using Eq. 6. We used data of Masuda et al. (1997) for quartz at 800-1000 ${ }^{\circ}$, Evans et al. (2001) for olivine at $1300^{\circ} \mathrm{C}$ and Azuma et al. (2012) for ice at $-20^{\circ} \mathrm{C}$. Note that $J_{S S} \mathrm{x} M_{S S}$ is strongly temperature-dependent, in particular because of the temperature dependence of $M$ (Tullis and Yund, 1982; Masuda et al., 1997; Evans et al., 2001). (JSS $x$ MSS) ELLE can be determined in essentially the same way by performing a numerical grain growth simulation with a pure, single-phase solid. It has been shown before that the ELLE routine results in a linear growth of the grain area, as expected from Eq. 6 (Bons et al., 2001). Using the effective $\left(J_{S S} x M_{S S}\right)_{E L L E}, P_{k i n}$ can be determined for the various simulations.

Using $P_{k i n}$ calculated for the different numerical simulations, it is possible to propose a "deformation regime map" that shows the transition between a deformation-dominated system (regime I) and a dynamic recrystallisation-dominated system (regimes IIa and IIb) considering a dihedral angle of $\omega=30^{\circ}$ for olivine-basaltic melt, (Fig.7a) and quartz-silicic melt (Fig.7c), or considering a $\omega=173^{\circ}$ for olivine-metallic melt (Fig.7b), and ice-air bubble aggregates (Fig.7d). The numerical simulations roughly span the transition from the deformation-dominated regime I to the $D R X$-dominated regime II. The transition, using kinematic scaling of the simulations (Eq. 5), is plotted as a function of the radius of curvature of the solid-melt boundary versus strain rate in Fig. 7. The transition from one regime to the other is not sharp, but roughly spans over one to two orders of magnitude in strain rate. At a given strain rate, the transition is at larger grain sizes for quartz and ice than for olivine.

\subsubsection{Regime I: deformation-controlled}

In the deformation-controlled regime, dynamic recrystallisation is too slow to counteract the shearing of melt pockets. The initial shape of melt pockets, and therefore the resulting dihedral angle, is not important. This is because pockets get stretched continuously without significant shape recovery by grain boundary migration. The aggregate develops a strong anisotropy in such cases (Takeda and Griera, 2006; Dabrowski et al., 2012). As this anisotropy starts at a high angle to the maximum compressive stress, the aggregate initially hardens before weakening sets in. Although not reached in the simulations, it is expected that stretched melt pockets will eventually merge into melt films parallel to the shear plane, causing a dramatic weakening of the aggregate (e.g. Vigneresse et al., 1996; Rosenberg and Handy, 2000). Regime I is favoured by high strain rates and/or large grain sizes (Fig. 7). Typical examples are Simulations $1,2,\left(\phi=10 \%\right.$ or $20 \%, \omega=30^{\circ}$ and $N_{D R X}=0.1$; see Fig.7a, c) or 9 and $10\left(\phi=10 \%\right.$ or $20 \%, \omega=173^{\circ}$ and $N_{D R X}=0.1$; see Fig. $\left.7 \mathrm{~b}, \mathrm{~d}\right)$.

\subsubsection{Regime IIa: DRX-controlled for low dihedral angle}

Regime IIa prevails when the strain rate is so slow that $D R X$ can counteract the stretching of melt pockets and these can retain their concave shape with a dihedral angle of $\omega \sim 30^{\circ}$. Simulations 3 and $4\left(\phi=10 \%\right.$ or $20 \%, \omega=30^{\circ}$ and $N_{D R X}=10$; Table 1$)$ are in the transition between Regime I and IIa (Fig.7a, c), where melt pockets are more elongated for simulations with low percentage of melt (Fig.2c). Typical examples of Regime IIa are Simulations 5, 6, 7 and $8\left(\phi=10 \%\right.$ or $20 \%, \omega=30^{\circ}$ and $N_{D R X}=100$ or 1000 ; Fig. $\left.7 \mathrm{a}, \mathrm{c}\right)$. As solid grains get flattened in the shortening direction and melt pockets reside at triple junctions, melt pockets tend to get connected in the shortening direction forming elongate melt pools oriented at high angles to 
the shear plane (Fig. 2c-e columns I and II). As these melt pools are unfavourably oriented to accommodate shearing, they do not cause a significant weakening of the aggregate. A dynamic equilibrium is expected to set in with ongoing formation, rotation and destruction of melt pools. Mechanically, the effect of strain is a minor transient weakening before steady state is reached.
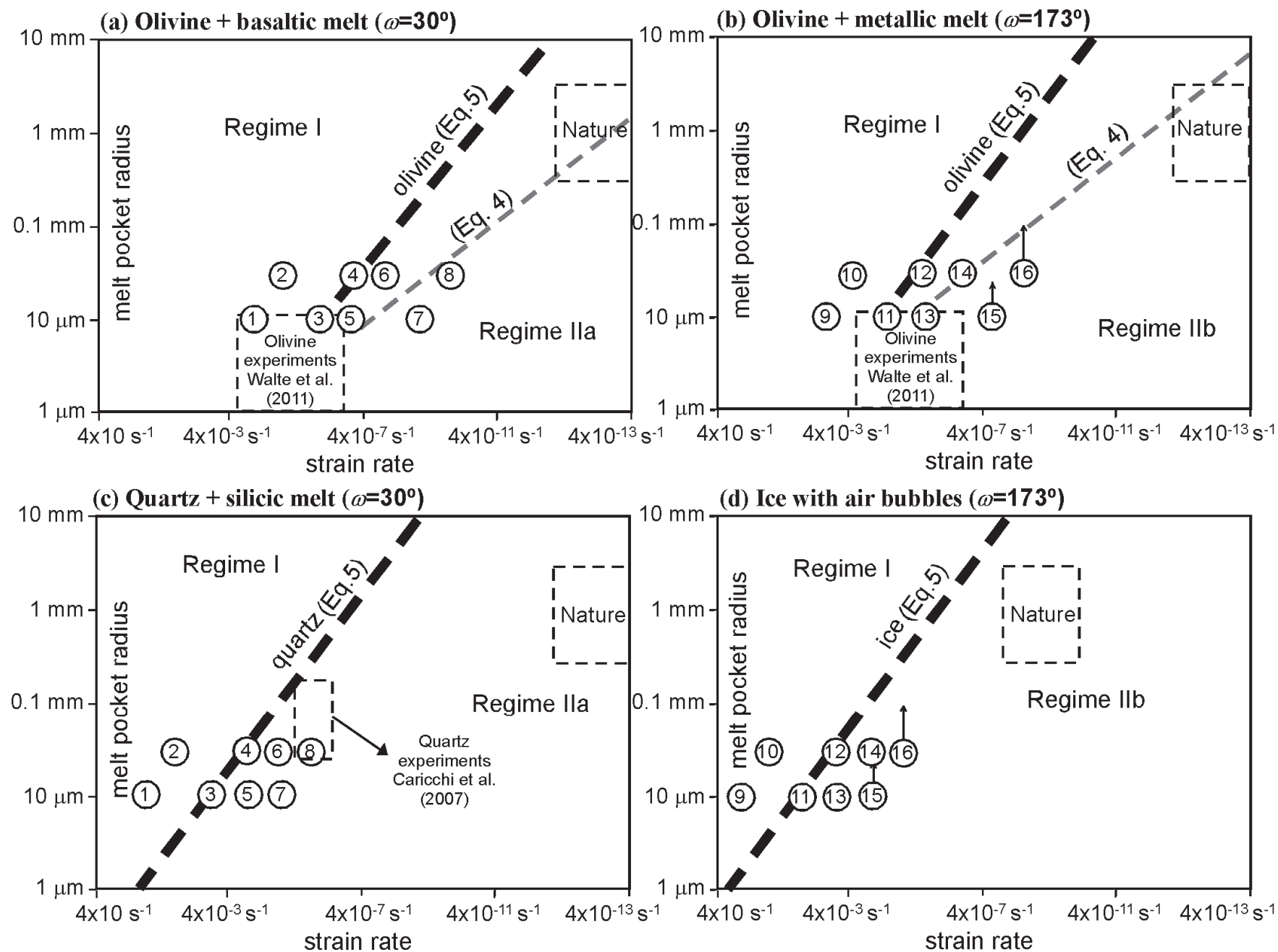

(d) Ice with air bubbles $\left(\omega=173^{\circ}\right)$

Figure 7. Transition between the deformation- and $D R X$ - controlled regimes predicted from the simulations using a kinematic scaling law for $P_{k i n}=1$ (Eq. 5) for (a) olivine with basaltic melt $\left(\omega=30^{\circ}\right)$, (b) olivine with metallic melt $\left(\omega=173^{\circ}\right)$, (c) quartz with silicic melt $\left(\omega=30^{\circ}\right)$ and $(\mathrm{d})$ ice with air bubbles. The transition between stress- and surface tension-controlled regimes using $P_{t h}=1$ (Eq.4) is from Walte et al., 2011. Experiments at this transition for olivine + FeS-melt of Walte et al. (2011) and quartz bearing melt experiments of Caricchi et al. (2007) are shown, together with the associated transition according to the thermodynamic scaling law (Eq. 5). Initial microstructures of simulations are shown in in circles. The changes in melt pocket radius during deformation in simulations 15 and 16 are indicated by arrows.

In this regime, $D R X$ is expected to have a significant effect on permeability, which becomes anisotropic. The maximum permeability develops at a high angle to the stretching direction, which may play a role in focusing melt flow (Katz et al., 2006). Since melt is not fully connected in our 2D models, the formation of melt pools is here solely an effect of connecting melt pockets, and not of proper porous flow through melt pockets (Spiegelman, 2003). Although the representative volume element in the simulations presented is not large enough, we can assume that the small-scale melt pools may, however, play a role in the formation of larger intergranular melt-enriched shear bands (i.e., shear bands larger than the grain size) (Walte et al., 2005; Kohlstedt and Holtzman, 2009). 
When the melt fraction is sufficiently interconnected, the melt can accommodate most of the deformation. Stress and strain rate in the solid are now reduced, resulting in less dynamic recrystallisation (Mecklengurgh et al., 2003; Rutter et al., 2006) We do not observe this effect in our simulations as the solid maintains a load-bearing framework at all times at the melt fractions used in our 2-D simulations. Therefore, the solid continues accommodating a significant amount of strain and keeps recrystallising.

\subsubsection{Regime IIb: DRX-controlled for high dihedral angle}

At high dihedral angles, $D R X$ enables melt pockets to fully retain their convex shape (Fig. 3de). The compact shape reduces melt pocket connectivity. Melt pockets are not inert, but are dragged by solid-solid boundaries (Roessiger et al. 2014). This process leads to their occasional merging, but without forming elongate melt pools. The bulk strength hardly changes with strain, since only the size distribution of melt pockets changes, but not their shape. Simulations 11 and $12\left(\phi=10 \%\right.$ or $20 \%, \omega=173^{\circ}$ and $N_{D R X}=10$; Table 1) are initially in the transition of between Regime I and IIb (Fig.7b, d). However, melt pocket radii increase during deformation due melt pocket merging, moving these simulations into the deformationcontrolled Regime I, which is consistent with melt pockets shape shown in Fig.3c. Typical examples of $D R X$-control are Simulations 13 and $14\left(\phi=10 \%\right.$ or $20 \%, \omega=173^{\circ}$ and $N_{D R X}=100$; Table 1; Fig.7b, d), and more markedly Simulations 15 and $16\left(\phi=10 \%\right.$ or $20 \%, \omega=173^{\circ}$ and $N_{D R X}=1000$; Table 1; Fig. 7b, d).

A similar behaviour has been described in aggregates containing melt with a high dihedral angle (Walte et al., 2011). At natural strain rates, sulphur-poor Fe alloys that have a very high dihedral angle $\left(\omega>130^{\circ}\right)$ are inferred to behave essentially like spherical inclusions dragged passively within the matrix (Walte et al., 2011). Ice with air bubbles that constitutes approximately the upper $600-1200 \mathrm{~m}$ of polar ice sheets, depending on pressure and temperature conditions, (Faria et al., 2014; Uchida et al., 2014) is another natural case evolving into regime IIb. Grain sizes here are of the order of $\mathrm{mm}$ and strain rates $<10^{-11} \mathrm{~s}^{-1}$, where regime-IIb behaviour is expected according to Fig. 7d. Bubbles are almost spherical in this domain, indicating that they do not cause a major change in ice rheology (Bendel et al., 2013; Roessiger et al., 2014; Steinbach et al., 2017). Bubbles in much faster flowing mountain glaciers, on the other hand, are usually elongated (Kerch, 2017).

Walte et al. (2011) carried out experiments on olivine- FeS melt systems that spanned the transition between deformation- and $D R X$-dominated behaviour (regimes I and II). The transition at strain rates of $10^{-5}$ to $10^{-6} \mathrm{~s}^{-1}$ at melt pocket sizes of the order of microns is as predicted in our simulations. Using the thermodynamic scaling parameter $\left(P_{t h}\right)$, Walte et al. (2011) predict mantle convection involving high-dihedral angle melts (grain sizes in the order of $\mathrm{mm}$, and strain rates $\leq 10^{-12} \mathrm{~s}^{-1}$ ) to be close to the transition between regimes IIb and I (Fig. $7 b$ ). In systems with a low dihedral angle such as olivine - basalt the boundary would be shifted to the right (Fig. 7a) to enlarge the deformation dominated regime, meaning that both experimental studies and nature would normally lie in deformation dominated regime I with the possible exception of very low melt-fractions $<1 \%$. These results largely confirmed the assessment by Kohlstedt and Holtzman (2009), who suggested that melt-present mantle deformation would occur in regime $\mathrm{I}$ as experimental studies considering both thermodynamic and kinematic scaling. Hence, melt-connectivity and solid-melt microstructures in geological systems (e.g. the asthenosphere) would be largely similar to experimental studies. However, this paradigma is challenged by scaling our numerical 
simulations with the kinematic scaling parameter $\left(P_{k i n}\right)$, which would place mantle convection well into regime II (Fig. 7). That would mean that most natural cases would lie between the two scaling lines. If so, caution must be taken when assuming a direct similarity between experiments and nature. Since the current experimental data is compatible with both scaling approaches and the difference lies in the slope between the regimes, our predictions can only be tested and refined with careful experimental studies that explore the boundary between the different regimes with a wider range of strain rates. One problem, however, is that the two regime boundaries for olivine-melt systems cross at about the conditions of typical experiments with olivine. These experiments may, therefore, not be suitable to determine whether $P_{t h}$ or $P_{\text {kin }}$ is the appropriate scaling parameter. Experiments on different mineral systems, as well as numerical modelling as presented here may help to resolve this issue.

In quartz-dominated partially molten rocks, such as migmatites described in the core of hot orogens (Schulmann et al., 2008), melt pockets tend to form veins parallel to the shortening direction in aggregates with ca. $100 \mu \mathrm{m}$ grain size at relatively low strain rates (see Fig. 7c). These structures confirm that mode IIa could be the prevailing strain-melt interaction mode in natural migmatites. Our kinematic scaling suggests that ice with air bubbles in ice sheets (grain size in the order of mm's) is mostly in regime IIb in the centre of ice sheets where deep drill cores are available (strain rates generally $<10^{-10} \mathrm{~s}^{-1}$ ) (Fig.7d). As expected, air bubbles are spherical here. Mountain glaciers with similar grain sizes, but much higher strain rates, can have elongated bubbles, indicative of Regime I.

\section{Conclusions}

Our numerical simulations couple viscous deformation by dislocation glide with simultaneous dynamic recrystallisation $(D R X)$ driven by strain and surface energy, leading to grain boundary migration and intracrystalline recovery. The results demonstrate that $D R X$ significantly influences the microstructural and rheological behaviour of partially molten rocks when it competes with deformation (in the $D R X$-controlled regime II). $D R X$ reduces the ability of deforming partially molten aggregates to form through-going shear bands. Instead, melt pools continually form and get destroyed when dihedral angles are low (concave melt pockets with $\omega<30^{\circ}$ ). This causes limited strain softening, compared to strain-dominated behaviour (regime I). The compact shape of high-dihedral angle melt pockets inhibits the formation of melt pools. As a consequence, there is almost no microstructure change at high relative $D R X$ rates and only a very minor change in bulk strength is observed as not the shape, but the size distribution of the melt pockets changes with strain.

\section{Acknowledgements}

This work was founded by the joint project "Rheology of the continental crust in collision", funded by the Procope scheme of PHC Egide in France and by the DAAD PPP scheme in Germany. M-GL acknowledges the support of the Juan de la Cierva programme of the Government of Spain's Ministry for Science, Innovation and Universities. EGR acknowledges the support of the Beatriu de Pinós programme of the Government of Catalonia's Secretariat for Universities and Research of the Department of Economy and Knowledge (2016 BP 00208). This work benefited from discussions with Pi L. Jolivet and E. Burov within the ERC project RHEOLITH. We thank Elisabetta Mariani and Marcin Dabrowski for their helpful comments, together with the editorial guidance of Dave Healy and Bill Dunne. 


\section{References}

Ashby, M. F. 1970. The deformation of plastically non-homogeneous materials. Philosophical Magazine, 21(170), 399-424.Azuma, N., Miyakoshi, T., Yokoyama, S., Takata, M., 2012. Impeding effect of air bubbles on normal grain growth of ice. Journal of Structural Geology, 42, 184-193.

Becker, J.K., Bons, P.D., Jessell, M.W. 2008. A new front-tracking method to model anisotropic grain and phase boundary motion in rocks. Computers \& Geosciences, 34, 201-212

Bendel, V., Ueltzhöffer, K. J., Freitag, J., Kipfstuhl, S., Kuhs, W. F., Garbe, C. S., Faria, S. H. 2013. Highresolution variations in size, number and arrangement of air bubbles in the EPICA DML (Antarctica) ice core. Journal of Glaciology, 59(217), 972-980.

Berg, M. T., Bromiley, G. D., Butler, I. B., Frost, M., Bradley, R., Carr, J., Perrillat, J. P. 2017. Deformationaided segregation of Fe-S liquid from olivine under deep Earth conditions: Implications for core formation in the early solar system. Physics of the Earth and Planetary Interiors, 263, 38-54.

Berthé, D., Choukroune, P., Jégouzo, P. 1979. Orthogneiss, mylonite and non coaxial deformation of granites: the example of the South Armorican Shear Zone. Journal of Structural Geology, 1(1), 31-42.

Bons, P.D., Cox, S.J.D. 1994. Analogue experiments and numerical modelling on the relation between microgeometry and flow properties of polyphase materials. Materials Science and Engineering A 175, 237-245.

Bons, P.D., Jessell, M.W., Evans, L., Barr, T.D., Stüwe, K. 2001. Modelling of anisotropic grain growth in minerals. Geological Society of America Memoir 193, 39-49

Bons, P.D., Koehn, D., Jessell, M.W. 2008. Microdynamic Simulation. Lecture Notes in Earth Sciences 106, Springer, Berlin. 405 pp.

Bulau, J.R., Waff, H.S., Tyburczy, J.A. 1979. Mechanical and thermodynamic constraints on fluid distribution in partial melts. Journal of Geophysical Research, Solid Earth, 84(B11), 6102-6108.

Caricchi, L., Burlini, L., Ulmer, P., Gerya, T., Vassalli, M., Papale, P. (2007). Non-Newtonian rheology of crystal-bearing magmas and implications for magma ascent dynamics, Earth Planet. Sci. Lett., 264, 402419 ,

Cooper, R.F., Kohlstedt, D.L. 1984. Solution-precipitation enhanced diffusional creep of partially molten olivine-basalt aggregates during hot-pressing. Tectonophysics, 107, 207-233.

Cerantola, V., Walte, N. P., Rubie, D. C. 2015. Deformation of a crystalline olivine aggregate containing two immiscible liquids: Implications for early core-mantle differentiation. Earth and Planetary Science Letters, 417, 67-77.

Dabrowski, M., Schmid, D.W., Podladchikov, Y.Y. 2012. A two-phase composite in simple shear: effective mechanical anisotropy development and localization potential.

J. Geophys. Res. 117, B08406. https://doi.org/10.1029/2012JB009183.

Evans, B., Renner, J., Hirth, G. 2001. A few remarks on the kinetics of static grain growth in rocks. International Journal of Earth Sciences, 90, 88-103.

Dabrowski, M., Schmid, D.W., Podladchikov, Y.Y. 2012. A two-phase composite in simple shear: effective mechanical anisotropy development and localization potential. J. Geophys. Res. 117, B08406. doi:10.1029/2012JB009183.

Faria, S.H., Weikusat, I., Azuma, N. 2014. The microstructure of polar ice. Journal of Structural Geology, 61, 220.

Faul, U.H., Toomey, D.R., Waff, H.S. 1994. Intergranular basaltic melt is distributed in thin, elongated inclusions. Geophys. Res. Lett. 21, 29-32.

Gao, H., Huang, Y., Nix, W. D., Hutchinson, J. W. 1999. Mechanism-based strain gradient plasticity-I. Theory. Journal of the Mechanics and Physics of Solids, 47(6), 1239-1263.

Gomez-Rivas, E., Griera, A., Llorens, M.-G., Bons, P. D., Lebensohn, R. A.,Piazolo, S. 2017. Subgrain Rotation Recrystallization During Shearing: Insights from Full-Field Numerical Simulations of Halite Polycrystals. Journal of Geophysical Research: Solid Earth, 122(11), 8810-8827.

Griera, A., Bons, P.D., Jessell, M.W., Lebensohn, R.A., Evans, L. Gomez-Rivas, E. 2011. Strain localization and porphyroclast rotation. Geology, 39, 275-278.

Griera, A., Llorens, M.-G., Gomez-Rivas, E., Bons, P.D., Jessell, M.W., Evans, L.A., Lebensohn, R. 2013. Numerical modelling of porphyroclast and porphyroblast rotation in anisotropic rocks. Tectonpophysics, 587, 4-29

Groebner, N., Kohlstedt, D.L. 2006. Deformation-induced metal melt networks in silicates: implications for core-mantle interactions in planetary bodies. Earth and Planetary Science Letters, 245, 571-580.

Handy, M.R., 1990. The exhumation of cross sections of the continental crust: structure, kinematics and rheology. In: Salisbury, M.H., Fountain \& D.M. (Eds.). Exposed cross sections of the continental crust. Kluwer, Dordrecht, 485-507. 
Hernlund, J.W., Houser, C. 2008. On the distribution of seismic velocities in Earth's deep mantle. Earth Planet. Sci. Lett. 265, 423-437.

Hernlund, J. W., Tackley, P. J. 2007. Some dynamical consequences of partial melting in Earth's deep mantle. Physics of the Earth and Planetary Interiors, 162(1-2), 149-163.

Hollister, L., Crawford, M. L. 1986. Melt-enhanced deformation: A major tectonic process. Geology, 14, 55-59.

Holtzman, B.K., Kohlstedt, D.L., Zimmerman, M.E., Heidelbach, F., Hiraga,T. Hustoft, J. 2003. Melt Segregation and Strain Partitioning: Implications for Seismic Anisotropy and Mantle Flow. Science, 301, 1227-1230.

Hustoft, J., Scott, T., Kohlstedt, D.L. 2007. Effect of metallic melt on the viscosity of peridotite. Earth and Planetary Science Letters 260, 355-360.

Jessell, M.W., Bons, P., Evans, L., Barr, T., Stüwe, K. 2001. Elle: the numerical simulation of metamorphic and deformation microstructures. Computers and Geosciences, 27, 17-30.

Jessell, M.W., Bons, P.D., Griera, A., Evans, L.A., Wilson, C.J.L. 2009. A tale of two viscosities. Journal of Structural Geology, 31, 719-736.

Karato, S. I. 2012. Deformation of earth materials: an introduction to the rheology of solid earth. Cambridge University Press.

Katz, R.F., Spiegelman, M., Holtzman, B. 2006. The dynamics of melt and shear localization in partially molten aggregates. Nature, 442, 676-679.

Kerch, J.K. 2017. Crystal-orientation fabric variations on the cm-scale in cold Alpine ice: Interaction with paleo-climate proxies under deformation and implications for the interpretation of seismic velocities. PhD Thesis. DOI: 10.11588/heidok.00022326

Kohlstedt, D.L., Holtzman, B.K. 2009. Shearing melt out of the Earth: An experimentalist's perspective on the influence of deformation on melt extraction. Annual Review of Earth Planetary Sciences, 37, 561-93.

Labrousse, L., Prouteau, G., Ganzhorn, A.C. 2011. Continental exhumation triggered by partial melting at ultrahigh pressure. Geology, 39, 12, 1171-1174.

Laporte, D., Watson, E. B. 1995. Experimental and theoretical constraints on melt distribution in crustal sources: the effect of crystalline anisotropy on melt interconnectivity. Chemical Geology, 124, 161-184.

Lay, T., Garnero, E. J., Williams, Q. 2004. Partial melting in a thermo-chemical boundary layer at the base of the mantle. Physics of the Earth and Planetary Interiors, 146(3-4), 441-467.

Lebensohn, R.A. 2001. N-site modelling of a 3D viscoplastic polycrystal using fast Fourier transform. Acta Materialia, 49(14), 2723-2737.

Lebensohn, R.A., Brenner, R., Castelnau, O., Rollett, A.D. 2008. Orientation image-based micromechanical modelling of subgrain texture evolution in polycrystalline copper. Acta Materialia, 56(15), 3914-3926. (doi: 10.1016/j.actamat.2008.04.016).

Lebensohn, R. A., Idiart, M., Castañeda, P. P., Vincent, P.-G. 2011. Dilatational viscoplasticity of polycrystalline solids with intergranular cavities, Philos. Maga., 91, 3038-3067.

Lebensohn, R. A., Escobedo, J. P., Cerreta, E. K., Dennis-Koller, D., Bronkhorst, C. A., Bingert, J. F. 2013. Modeling void growth in polycrystalline materials, Acta Mater., 61, 6918-693.

Llorens, M.-G., Bons, P.D., Griera, A., Gomez-Rivas, E. 2013a. When do folds unfold during progressive shearing? Geology 41, 563-566

Llorens, M.-G., Bons, P.D., Griera, A., Gomez-Rivas, E. 2013b. Single layer folding in simple shear. Journal of Structural Geology. 50, 209-220.

Llorens, M. G., Griera, A., Bons, P. D., Roessiger, J., Lebensohn, R., Evans, L., Weikusat, I. 2016a. Dynamic recrystallisation of ice aggregates during co-axial viscoplastic deformation: a numerical approach. Journal of Glaciology 62, 359-377

Llorens, M. G., Griera, A., Bons, P. D., Lebensohn, R. A., Evans, L. A., Jansen, D., Weikusat, I. 2016b. Full field predictions of ice dynamic recrystallisation under simple shear conditions. Earth and Planetary science letters 450, 233-242.

Llorens, M.G., Griera, A., Steinbach, F., Bons, P.D., Gomez-Rivas, E., Jansen, D., Roessiger, J., Lebensohn, R.A., Weikusat, I. 2017. Dynamic recrystallization during deformation of polycrystalline ice: insights from numerical simulations. Philosophical Transactions of the Royal Society el London A, 375 20150346.

Madi, K., Forest, S., Cordier, P., Boussuge, M. 2005. Numerical study of creep in two-phase aggregates with a large rheology contrast: implications for the lower mantle. Earth and Planetary Science Letters, 237(1-2), 223-238.

Mancktelow, N. S. 2002. Finite-element modelling of shear zone development in viscoelastic materials and its implications for localisation of partial melting. Journal of Structural Geology, 24(6-7), 1045-1053.

Masuda, T. 1997. Grain-boundary migration of quartz during annealing experiments at high temperatures and pressures, with implications for metamorphic geology. Journal of Metamorphic Geology, 15, 311-322. 
Mei, S., Bai, W., Hiraga, T., Kohlstedt, D. L. 2002. Influence of melt on the creep behavior of olivine-basalt aggregates under hydrous conditions. Earth and Planetary Science Letters, 201(3-4), 491-507.

Mecklenburgh, J., Rutter, E. H. 2003. On the rheology of partially molten synthetic granite. Journal of Structural Geology, 25(10), 1575-1585.

Mierdel, K., Keppler, H., Smyth, J. R., Langenhorst, F. 2007. Water solubility in aluminous orthopyroxene and the origin of Earth's asthenosphere. Science, 315(5810), 364-368.

Misra, S., Burlini, L., Burg, J. P. 2009. Strain localization and melt segregation in deforming metapelites. Physics of the Earth and Planetary Interiors, 177(3-4), 173-179.

Mullins, W.W. 1989. Estimation of the geometrical rate-constant in idealized 3 dimensional grain-growth. Acta Metallurgica, 37, 2979-2984.

Qi, C., Kohlstedt, D. L., Katz, R. F., Takei, Y. 2015. Experimental test of the viscous anisotropy hypothesis for partially molten rocks. Proceedings of the National Academy of Sciences, 112(41), 12616-12620.

Qi, C., Hansen, L. N., Wallis, D., Holtzman, B. K., Kohlstedt, D. L. 2018. Crystallographic preferred orientation of olivine in sheared partially molten rocks: The source of the ,a-c switch“. Geochemistry, Geophysics, Geosystems, 19. http://doi.org/10.1002/2017GC007309

Ran, H., Bons, P.D., Wang, G., Steinbach, F., Finch, M. Griera, A., Gomez-Rivas, E., Llorens, M.-G., Ran, S., Liang, X., Zhou, J. 2018. High-strain deformation of conglomerates: numerical modelling, strain analysis, and an example from the Wutai Mountains, North China Craton. J. Struct. Geol.114, 222-234 doi: https://doi.org/10.1016/j.jsg.2018.06.018

Roessiger, J., Bons, P.D., Griera, A., Jessell, M.W., Evans, L. Montagnat, M., Kipfstuhl, S., Faria, S.H., Weikusat, I. 2011. Competition between grain growth and grain size reduction in polar ice. Journal of Glaciology 57, 942-948.

Roessiger, J., Bons, P.D., Faria, S.H. 2014. Influence of bubbles on grain growth in ice. Journal of Structural Geology. Journal of Structural geology 61, 123-132.

Rosenberg, C.L. 2001. Deformation of partially molten granite: a review and comparison of experimental and natural case studies. International Journal of Earth Sciences 90, 60-76.

Rosenberg, C.L., Handy, M.R. 2005. Experimental deformation of partially melted granite revisited: implications for the continental crust. Journal of Metamorphic Geology, 23, 19-28

Rudnick, R.L., 1995. Making continental crust. Nature, 378, 571-578.

Rutter, E. H., Brodie, K. H., Irving, D. H. 2006. Flow of synthetic, wet, partially molten "granite" under undrained conditions: an experimental study. Journal of Geophysical Research: Solid Earth, 111(B6).

Schulmann, K., Martelat, J. E., Ulrich, S., Lexa, O., Štípská, P., Becker, J. K. 2008. Evolution of microstructure and melt topology in partially molten granitic mylonite: Implications for rheology of felsic middle crust. Journal of Geophysical Research: Solid Earth, 113(B10).

Scott, T., Kohlstedt, D.L. 2006. The effect of large melt fraction on the deformation behavior of peridotite. Earth and Planetary Science Letters, 246, 177-187.

Sifré, D., Gardés, E., Massuyeau, M., Hashim, L., Hier-Majumder, S., Gaillard, F. 2014. Electrical conductivity during incipient melting in the oceanic low-velocity zone. Nature, 509(7498), 81.

Spiegelman, M. 2003. Linear analysis of melt band formation by simple shear. Geochemistry, Geophysics, Geosystems 4, 8615, doi:10.1029/2002GC000499.

Stevenson, D. J. 1990. in Origin of the Earth (eds Newsom, H. E. \& Drake, J. H.) 231-249 (Oxford Univ. Press, New York)

Steinbach, F., Bons, P. D., Griera, A., Jansen, D., Llorens, M. G., Roessiger, J., Weikusat, I. 2016. Strain localization and dynamic recrystallization in the ice-air aggregate: a numerical study. The Cryosphere, 10(6), 3071.

Steinbach, F., Kuiper, E.J.N., Eichler, J., Bons, P.D., Drury, M.R., Griera, A., Pennock, G.M., Weikusat, I. 2017. The Relevance of Grain Dissection for Grain Size Reduction in Polar Ice: Insights from Numerical Models and Ice Core Microstructure Analysis. Frontiers in Earth Sci. 5, 66. Doi: 10.3389/feart.2017.00066.

Takeda, Y.-.T., Griera, A. 2006. Rheological and kinematical responses to flow of two-phase rocks. Tectonophysics, 427, 95-114.

Takeda, Y.-T., Obata, M. 2003. Some comments on the rheologically critical melt percentage. Journal of Structural Geolology, 25, 813-818.

Terasaki, H., Urakawa, S., Funakoshi, K., Nishiyama, N., Wang, Y., Nishida, K., Sakamaki, T., Suzuki, A., Ohtani, E. 2009. In situ measurement of interfacial tension of $\mathrm{Fe}-\mathrm{S}$ and $\mathrm{Fe}-\mathrm{P}$ liquids under high pressure using X-ray radiography and tomography techniques. Physics of the Earth and Planetary Interiors, 174(14), pp.220-226.

Teyssier, C., Whitney, D. 2002. Gneiss domes and orogeny. Geology, 30, 1139-1142.

Todd, K. A., Watson, H. C., Yu, T., Wang, Y. 2016. The effects of shear deformation on planetesimal core segregation: Results from in-situ X-ray micro-tomography. American Mineralogist, 101, 1996-2004. 
Treagus, S. H., Lan, L. 2000. Pure shear deformation of square objects, and applications to geological strain analysis. Journal of Structural Geology, 22(1), 105-122.

Tullis, J., Yund, R. A. 1982. Grain growth kinetics of quartz and calcite aggregates. The Journal of Geology, 301-318.

Uchida, T., Yasuda, K., Oto, Y., Shen, R., Ohmura, R. 2014. Natural supersaturation conditions needed for nucleation of air-clathrate hydrates in deep ice sheets. Journal of glaciology, 60(224), 1111-1116.

Urai, J.L., Means, W.D., Lister, G.S. 1986. Dynamic recrystallization of minerals. Am. Geophys. Un. Geophys. Monogr. 36, 161-199.

Vanderhaeghe, O. 2009. Migmatites, granites and orogeny: Flow modes of partially-molten rocks and magmas associated with melt/solid segregation in orogenic belts. Tectonophysics, 477, 119-134.

Vielzeuf, D., Clemens, J.D., Pin, C., Moinet, E. 1990. Granites, granulites and crustal differentiation. In: Vielzeuf, D., Vidal, Ph. (Eds.). Granulites and crustal evolution. Kluwer. Dordrecht, 59-85.

Vigneresse, J.L., Barbey, P., Cuney, M. 1996. Rheoloical transitions during partial melting and crystallization with application to felsic magma segregation and transfer. Journal of Petrology 37, 1569-1600.

von Bargen, N., Waff, H. S.1986. Department of Geology, University of Oregon, Eugene. Journal of Geophysical Research, 91(B9), 9261-9276.

Walte, N.P., Bons, P.D., Passchier, C.W., Koehn, D. 2003. Disequilibrium melt distribution during static recrystallization. Geology 31, 1009-1012.

Walte, N.P., Bons, P.D., Passchier, C.W. 2005. Deformation of melt-bearing systems - insight from in situ grain-scale analogue experiments. Journal of Structural Geology 27, 1666-1679, http://dx.doi.org/10.1016/j.jsg.2005.05.006

Walte, N.P., Rubie, D.C., Bons, P.D., Frost, D.J. 2011. Deformation of a crystalline aggregate with a small percentage of high dihedral-angle liquid: Implications for core-mantle differentiation during planetary formation. Earth and Planetary Science Letters, 305, 124-134.

Whitney, D., Teyssier, C., Rey, P.F. 2009. The consequences of crustal melting in continental subduction. Lithosphere, 1, 323-327.

Wood, B. J., Walter, M. J., Wade, J. 2006. Accretion of the Earth and segregation of its core. Nature, 441(7095), 825. 